\title{
Identifying high residency areas of the threatened St. Lawrence beluga whale from fine-scale movements of individuals and coarse-scale movements of herds
}

\author{
Sébastien Lemieux Lefebvre ${ }^{1,3}$, Robert Michaud ${ }^{2}$, Véronique Lesage ${ }^{3, *}$, \\ Dominique Berteaux ${ }^{4}$
}

\author{
${ }^{1}$ Department of Natural Resource Sciences, McGill University, Ste. Anne de Bellevue, Quebec H9X 3V9, Canada \\ ${ }^{2}$ Group of Research and Education on Marine Mammals, Quebec G1R 1T5, Canada \\ ${ }^{3}$ Ministry of Fisheries and Oceans, Maurice Lamontagne Institute, Mont-Joli G5H 3Z4, Canada \\ ${ }^{4}$ Chaire de recherche du Canada en conservation des écosystèmes nordiques et Centre d'Études Nordiques, \\ Université du Québec à Rimouski, Rimouski G5L 3A1, Canada
}

\begin{abstract}
The development of high-performance tracking and analytical tools has greatly facilitated the study of animal movements, which, in turn, are increasingly employed to study habitat use. However, data on individual movements are rarely available at both broad spatial and temporal scales, limiting their utility for the study of habitat use at population levels. In this study, we propose a novel approach to investigate habitat profitability and population residency patterns by combining the analysis of fine-scale tracking data from individual animals with coarser, shortterm movement patterns of herds. We used this approach to identify areas of high residency (AHR) for the St. Lawrence beluga whale Delphinapterus leucas, a population classified as 'threatened' under the Canadian Species At Risk Act. We used radio telemetry and a first passage time approach to study the fine-scale daily movements of 30 belugas. Information obtained from these animals on variation of search effort during displacements, scales at which area-restricted search (ARS) occurred, and associated swimming speeds was used to grid our study area and define a criterion for high residency of beluga herds. The beluga herd database used to identify AHR was composed of 772 visual 'herd follows' covering a large portion of the beluga population summer distribution. Thirty-three ARS zones were identified at 2 different spatial scales ( 500 $\mathrm{m}$ and $\sim 1500 \mathrm{~m})$. Using these scales and the swimming speeds associated with ARS to study the residency of herds resulted in the identification of 28 AHRs used by beluga within their summer distribution.
\end{abstract}

KEY WORDS: Residency $\cdot$ Beluga whale $\cdot$ Delphinapterus leucas $\cdot$ Movement $\cdot$ St. Lawrence estuary $\cdot$ First-passage time $\cdot$ Area-restricted search

\section{INTRODUCTION}

Most species live in complex heterogeneous environments consisting of a mosaic of habitats that individuals use for different functions. At any given time, the profitability of these habitats should depend on how well their available resources match individuals' life history needs. Both resources and needs change through space and time; thus habitat profitability varies, and individuals should move to optimize their use of the most profitable habitats. They usually do this by modulating transit times in the various habitats (Pyke 1978, Turchin 1991). Under these assumptions, residency of individuals is a proxy for habitat 
profitability, with residency expected to increase with profitability (Barraquand \& Benhamou 2008).

The combined movements of individuals define the distribution of populations (Turchin 1998, Russell et al. 2003). Over a given period, the residency pattern of a population will thus be the result of the summation of individuals' residency patterns. This summation is useful to conservation biologists because management decisions are usually taken at the scale of populations rather than individuals. Areas where a population shows high residency can be considered as generally profitable for individuals when they visit them. These areas are thus not defined solely from individual density or frequency of use and can help reveal important areas used by fewer individuals and/or for some rarer behaviour (e.g. calving areas). Despite the long recognized limitations in using proxies to infer habitat quality (Van Horne 1983, Johnson 2007), high residency areas can represent valuable tools to infer profitable (high quality) habitats when no direct measurements of habitat quality, individual fitness, and population demography are available. This could be particularly important for conservation, as the protection of habitats of higher quality can be critical for the survival of endangered populations.

The development of archival instruments that collect large amounts of accurate locations and of suitable tools for analysis has greatly facilitated the study of animal movements (Austin et al. 2004, Laidre et al. 2004, Jonsen et al. 2006, Pinaud \& Weimerskirch 2007). The analysis of first-passage time (FPT) was developed to study movement patterns in response to spatial heterogeneity and to identify area-restricted search (ARS) behaviour (Fauchald \& Tveraa 2003) and the scale at which it occurs. ARS is used by predators when foraging on prey patches, resulting in an increase in tortuosity of their movement and a reduction in speed to remain within the most profitable prey aggregations. This behaviour thus increases the residency of individuals in specific areas. The FPT approach has been developed to detect ARS of central place foragers (Fauchald \& Tveraa 2003, Pinaud \& Weimerskirch 2005, Fauchald \& Tveraa 2006, Pinaud \& Weimerskirch 2007). However, FPT could also be used in other contexts to detect any movement pattern leading to increased residency.

Although individual tracking provides a powerful means to study fine-scale behaviour/habitat relationships, logistic challenges and costs often limit the number of individuals that can be tracked and the usefulness of the technique to infer habitat use at the population level (Whitehead 2004). This is especially true in the context of cetacean research, where following focal groups or herds often provides more insight into population behaviour and distribution, since groups or herds are easier to encounter and follow, are less subject to selection bias, do not require individual recognition (which could be challenging in large groups), and often provide better data on incidence and changes of behavioural states (Whitehead 2004). In this context, long-term research projects on population distributions and behaviour based on group or herd follows represent a rich opportunity to study population-level habitat selection at multiple spatial and temporal scales (e.g. Cañadas \& Hammond 2008). However, current analytical tools for inferring movement patterns at the population level are not appropriate for populations in which tracking of fine-scale movements of many individuals is logistically difficult.

The St. Lawrence beluga whale population Delphinapterus leucas is listed as threatened under the Canadian Species At Risk Act and has not recovered despite 25 yr of protection (COSEWIC 2004). Reasons preventing their recovery may be related to the quality of available habitat. Therefore, there is an urgent need to identify important habitats for this population. As part of a long-term research program investigating the biology, ecology and behaviour of the St. Lawrence beluga whales, several hundreds of hours were spent during many years, predominantly during summer and early autumn, in search of opportunistic encounters with beluga herds. These sustained efforts resulted in several hundreds of herd encounters during which data on herd movement and habitat use were collected. In combination with these surveys, a number of individuals were equipped with VHF transmitters which provided precise data on individual movements. Based on these 2 datasets, our objective was to develop an approach to study population residency patterns and habitat profitability, using FPT analysis of the VHFtracking data to guide the analysis of coarse, shortterm movements of beluga herds from the St. Lawrence Estuary, Canada.

\section{MATERIALS AND METHODS}

\section{Study design}

We conducted both radio-tracking of individuals and visual tracking of herds (Fig. 1). We analyzed the resulting data in 3 steps. First, we used FPT analyses of individual movements to identify the swimming 


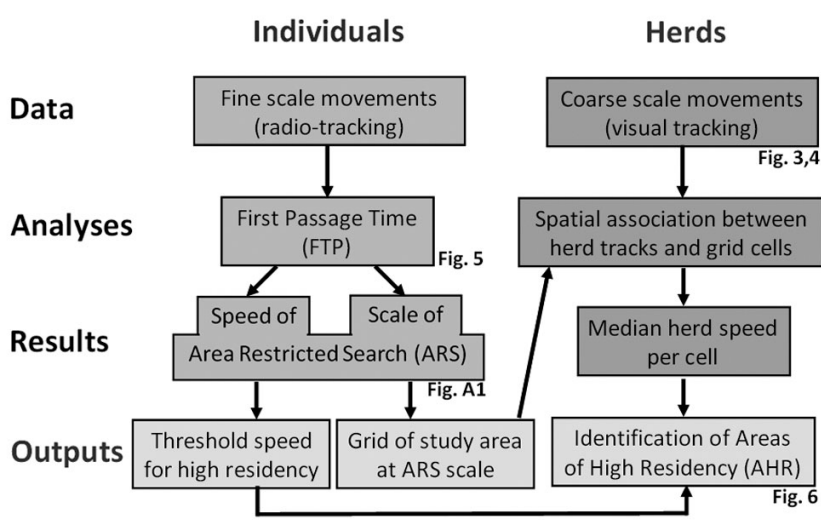

Fig. 1. Delphinapterus leucas. Study design: different steps of the analysis of movements and residency patterns of beluga whale individuals and herds

speeds and scales associated with ARS (Fig. 1). We could not separate foraging from non foraging movements, so ARS indicates any behaviour that increased residency.

Herd movements result from the combined movements of individuals in the herd. Therefore, in a second step, we used the swimming speed associated with individual ARS as a threshold to establish high residency (Fig. 1). We calculated this threshold criterion by resampling individual movements during ARS at the coarser temporal scale of herd visual tracking. In addition, we used the scale(s) associated with ARS to grid the study area at a scale relevant to the ecology of beluga whales (Fig. 1).

In a third step, we associated the movement patterns of herds with the formerly-generated grid. Using the swimming speed threshold established previously, we were able to identify cells characterised by high residency of herds and the beluga population (Fig. 1).

\section{Biology and range of the St. Lawrence beluga}

The St. Lawrence beluga whales in eastern Canada are year-round residents to the St. Lawrence River system and undertake only limited seasonal migrations. During summer, they occupy an area of approx. $2790 \mathrm{~km}^{2}$ in the St. Lawrence Estuary and Saguenay River, where their distribution is centered on the entrance of the river (Fig. 2). They move a few tens of kilometres downstream in the fall and winter, although their distribution at that time of year is poorly understood. In the spring, their distribution appears more widespread, with larger concentra-

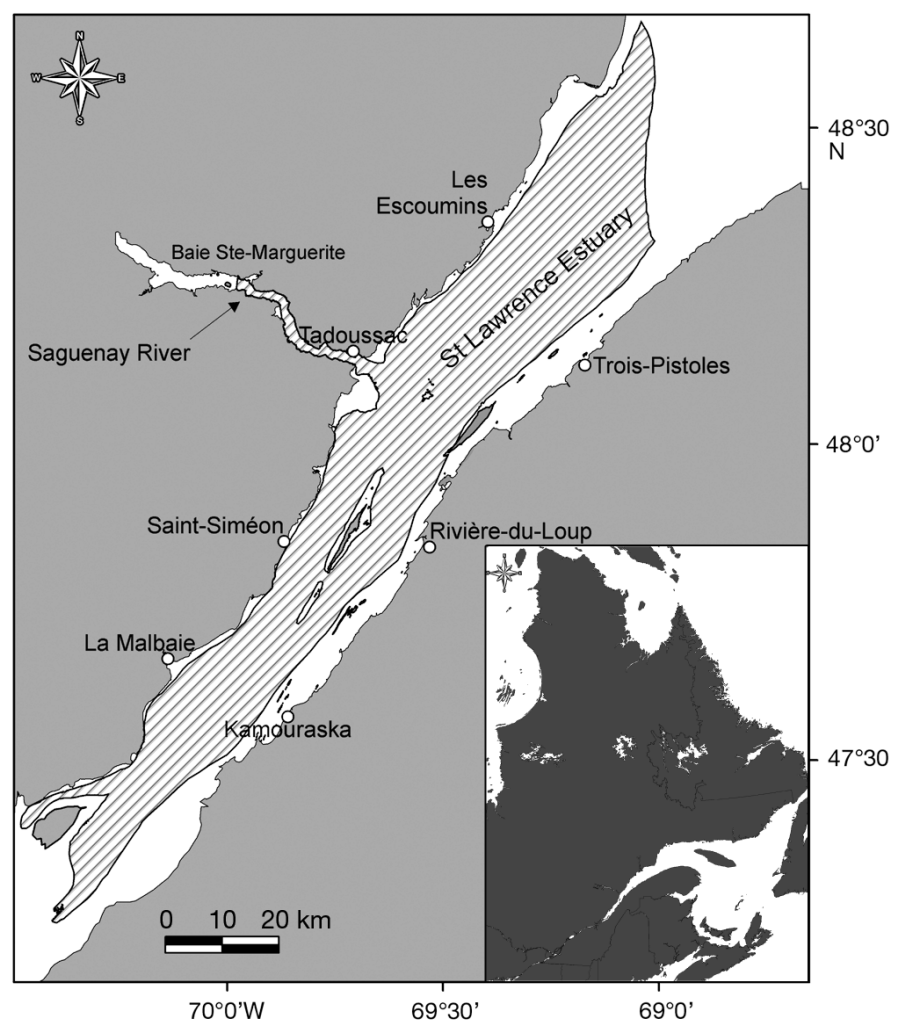

Fig. 2. Delphinapterus leucas. Summer distribution (hatched) of beluga whales in the St. Lawrence Estuary, Quebec, Canada

tions of individuals within the upstream Estuary. Beluga whales are considered opportunist feeders. Although their seasonal feeding cycles are not well understood, feeding locations probably vary seasonally according to the spatial and temporal availability of prey, but feeding likely occurs in all seasons (Vladykov 1946, V. Lesage unpubl. data).

A sexual segregation takes place during summer. Herds of white individuals, likely females, accompanied by juveniles and calves occupy the Upper Estuary while herds of large adults, likely males, occupy the Lower Estuary (Michaud 1993). However, both types of herds are encountered within the central portion of the Estuary and in the Saguenay River (see Fig. 7). Females reproduce every $3 \mathrm{yr}$, and attain sexual maturity between the ages of 8 and $14 \mathrm{yr}$, whereas males mature between 16 and 18 yr of age. Mating probably occurs from April through June, with calving taking place 12 to 15 mo later (June to September, but mostly in July to August). Nursing may last from 20 to $30 \mathrm{mo}$, possibly overlapping the following gestation period (Lesage \& Kingsley 1998). Calving and nursing areas are currently unknown, but the use of the shallower and warmer waters of the up- 
stream region of the Estuary by females with calves or juveniles during summer suggest this area might be important for this function (Mosnier et al. 2010).

\section{Data collection: individual radio-tracking}

From 2001 to 2005, we deployed VHF-TDR tags on individual beluga whales during herd follows. We selected candidate beluga herds from the central portion of the summer population distribution, where all gender and age classes were generally encountered (see Michaud 1993). Tags included a timedepth-velocity recorder (TDR Mk8, Wildlife Computers) and a $300 \mathrm{~g}$ radio transmitter (VHF, Telonics). Instruments were housed in a floating remotereleased package and were attached to individuals using a suction cup (Hooker \& Baird 1999). A magnesium cap, designed to corrode and release suction after 4 to $6 \mathrm{~h}$, served as a mechanism to retrieve tags from the whales.

We tagged and tracked beluga whales from a small vessel equipped with a 6-element Yagi antenna. Tags were attached using either a cross-bow or a $3 \mathrm{~m}$ pole. We usually tracked individuals from a distance of 400 to $600 \mathrm{~m}$. After each sequence of respirations, we recorded the position of the tracked individual relative to our vessel. Distances to the tracked individuals were estimated by trained observers, to provide precise distance measurements giving the range of observation kept during the tracking (400 to $600 \mathrm{~m})$. We then used the GPS position of the vessel, the distance separating it from the tagged beluga and the angle of the animal relative to true north to calculate the position of each tagged individual. We followed tagged individuals until dusk, release of tag, or loss of signal.

\section{Data collection: herd visual tracking}

We tracked over 1950 beluga herds during the summer or early fall of 1989 to 2008. One research team (GREMM, Tadoussac, Canada) acquired most of the data, but a second team (DFO, Mont-Joli, Canada) contributed to sampling in 2003 to 2005. We selected survey areas according to weather conditions, while avoiding resampling areas that were covered the previous days. Surveys were neither random nor systematic but covered the various sectors of a large portion of the population summer distribution and a broad range of habitats. Before 1996, the study area encompassed the full extent of the summer dis- tribution (ca. $2790 \mathrm{~km}^{2}$ ) but was limited to its central portion from 1996 to 2008 by the requirements of a concurrent study (carried out from the same boat) investigating social networking of specific sex- and age-classes. One or two observers conducted surveys (defined below) aboard a 9 to $10 \mathrm{~m}$ vessel, from a platform located $4 \mathrm{~m}$ above water.

We defined a herd as an assemblage of groups in which inter-group distances were small compared with the extent of the herd. Groups were composed of animals swimming within one beluga length of each other, generally in a coordinated fashion. We initiated a 'herd follow' once we encountered a herd. During the first $15 \mathrm{~min}$, we collected preliminary information on herd composition and size while maintaining a distance of 300 to $500 \mathrm{~m}$ from the herd. The research vessel then proceeded into the herd to collect data through various protocols such as photoidentification, biopsy sampling, and radio-tagging. Regardless of the protocol, we described herd characteristics in a consistent way every $30 \mathrm{~min}$. These summary surveys included the position, composition, movement, and behaviour of the herd. We also noted position of the research vessel and prevailing weather conditions. Herd follows lasted generally $3 \mathrm{~h}$ at most, but their duration varied depending on sampling protocols and prevailing field conditions.

\section{Data analysis: individual radio-tracking}

We first analysed individual tracking data with the first-passage time (FPT) approach. The FPT is the time required for an animal to cross a circle of a given radius $r$ (Johnson et al. 1992). A peak in relative variance among FPT values calculated at multiple scales (i.e. different $r$ values) indicates the scale at which restricted search patterns occurred (Fauchald \& Tveraa 2003). We used ArcGIS 9.1 (ESRI) to generate linearly interpolated paths from positional data of individuals. We calculated step lengths using the Hawth's analysis tool extension for ArcGIS. As the quality of FPT analyses depends on tracking duration and accuracy of positions of successive moves (Pinaud 2008), we dropped short tracking records ( $<15$ positions) from the analysis. In addition, to minimize errors associated with linear approximation, we segmented tracks when the interval between 2 consecutive positions exceeded $1 \mathrm{~h}$.

We interpolated segments to obtain a position every $50 \mathrm{~m}$, and calculated the FPT at each position for circles with $r$ of 200 to $3000 \mathrm{~m}$, in increments of $100 \mathrm{~m}$. Variance values were log-transformed to en- 
sure independence from $r$ (Fauchald \& Tveraa 2003). Following Bailey \& Thompson (2006), we identified circle radii associated with peaks in FPT variances as corresponding to the scale of restricted search behaviour (hereafter referred to as Var-max). This method identified the interpolated point with the highest FPT (at Var-max) as the centre of a circle (of radius $r_{\text {max }}$ ), delimiting intensively searched primary areas, hereafter called ARS zones (using the terminology of Pinaud \& Weimerskirch 2007). However, since ARS may occur more than once during a single tracking, we developed a method to identify multiple ARS zones within a given segment. This method, which is fully described in Appendix 1, uses piecewise regression models to identify break points within first-passage time values, allowing identification of values related to ARS behaviour and thus establishing the potential presence of multiple ARS zones.

We then calculated the criterion for high residency for the subsequent analysis of population residency pattern from herd follows (Fig. 2). For this calculation, it was first necessary to calculate the net displacement speeds of individually tracked belugas over a temporal scale comparable to the sampling interval used during herd follows, i.e. $30 \mathrm{~min}$. To achieve this, we re-sampled segments using $\sim 30 \mathrm{~min}$ windows and calculated the resulting net speed associated with these windows. We then retained only windows including $50 \%$ or more of time spent in an ARS zone. We used a $50 \%$ threshold given that we cannot obtain a clear indication as to where ARS began during herd follows, due to their coarser resolution. The $50 \%$ threshold thus allows taking into account transition periods, when herds might have been in ARS or transiting from or toward ARS activities. We next calculated the average speed within the retained windows for each ARS zone.

Using these average speeds, we calculated an overall value across individuals to obtain the final criterion for high residency using the following steps. Since more than one ARS zone were identified for some individuals (see 'Results'), we first randomly selected one ARS per individual to avoid an overrepresentation of individuals with multiple ARS, and compiled the associated average speed values. We then repeated this random selection 10 times, and then divided the 10 sets of averages into percentiles. We finally determined the 90th percentile (Method 5, SAS Institute 2003) of each of the 10 sets of values and averaged the selected final 10 values to obtain the criterion of high residency. This approach provides a conservative estimate of the speed associated with high residency in herds, as it is based on ARS in individuals, and takes into account the differences in ARS behaviour among individuals as well as the differences in sampling protocols between VHF tracking and herd follows.

\section{Data analysis: herd visual tracking}

Herd follows retained for analysis comprised at least 3 consecutive 'summary surveys' each separated by $30 \mathrm{~min}$. We calculated paths and associated movement parameters as for individual tracking data. We divided paths into segments of 2 successive positions representing the interval between 2 summary surveys. To represent the spread of the herd, we created around each segment a buffer of the size of the estimated herd radius (Fig. 3). We attributed to the entire buffered segment the herd speed during that segment. We excluded from analyses buffer sections overlapping with land.

To study herd movements at a scale likely relevant to belugas' perception of their environment, we divided the study area into cells of a size corresponding to the scales of ARS, as defined through the FPT analysis (i.e. twice the mean Var-max radius). We associated segments of herd follows with grid cells using the ArcGIS spatial-join tool. We averaged herd speed when 2 segments from the same herd follow overlapped. To conserve as many cells as possible while keeping cells where residency of herd could be

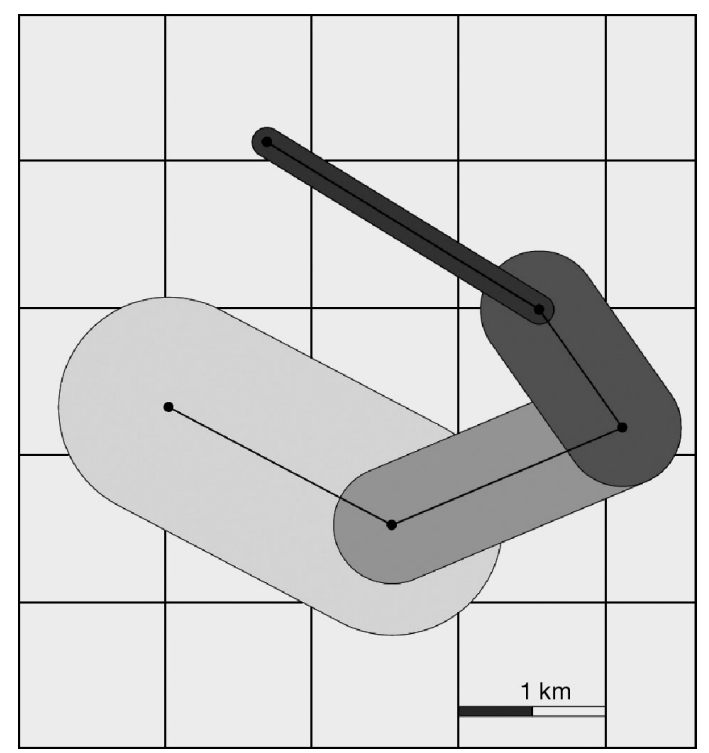

Fig. 3. Delphinapterus leucas. Displacement pattern of a beluga herd divided into 30 min segments (different greys) with their associated buffers. Buffer size corresponds to the herd radius 
calculated and compared, we analysed only cells visited by at least 3 herds (Fig. 4).

We determined areas of high residency (AHR) using net displacement speed of herds in each cell. We defined AHR as adjacent cells where $50 \%$ of the herds travelled at a speed equal to or slower than the criterion for high residency identified from the speed associated with ARS in individual beluga. We defined boundaries of AHR by grouping cells that were adjacent on at least one side. To limit the analysis to the main sectors, we retained only AHR composed of a least 2 cells.

We tested the sensitivity of the delimited AHR to the criteria used to define them in 2 ways. First, we changed the criterion using the net displacement speed associated with high residency of herds by using the lower and upper extremes of the 90th percentile from the 10 values obtained through the moving average analysis. Secondly, we changed the percentage of herds travelling below the net displacement speed threshold value by an arbitrary factor of $5 \%$, representing an interval similar to the difference taken to test the sensitivity to the speed threshold (see 'Results'). We finally tested the variation in AHR across years by repeating the analysis while grouping years into 3 periods: 1993-1997, 1998-2002 and 2003-2008. We selected periods so that sample size was large enough within each of them to allow adequate analysis of variation through time in the distribution of AHR.

\section{RESULTS}

\section{Individual radio-tracking}

Between June and October 2001 to 2005, we successfully tagged and tracked 44 belugas, for an average of $7 \mathrm{~h} 08 \mathrm{~min}$ (range: $0 \mathrm{~h} 30 \mathrm{~min}$ to $29 \mathrm{~h} 09 \mathrm{~min}$ ) (Table 1). Thirty of the 44 radio-tracked belugas provided 38 segments of sufficient duration $(\geq 15$ positions) for the analysis of fine-scale daily movements using the FPT approach. These segments were composed of an average of 43 positions (range: 15 to 110 positions) acquired over an average total non-linear distance of $23.4 \mathrm{~km}$ (range: 5.3 to $60.7 \mathrm{~km}$ ) and a period of $4 \mathrm{~h} 27 \mathrm{~min}$ (range: $0 \mathrm{~h} 41 \mathrm{~min}$ to $9 \mathrm{~h} 36 \mathrm{~min}$ ). The time interval between positions averaged 6 min $41 \mathrm{~s} \pm 5$ min $19 \mathrm{~s}$. The average swimming speed of individuals during follows was $5.8 \pm 1.7 \mathrm{~km} \mathrm{~h}^{-1}$ (range: 0.15 to $22.35 \mathrm{~km} \mathrm{~h}^{-1}$ ).

We identified a total of 17 peaks in relative variance of FPT (Var-max values), indicative of ARS.

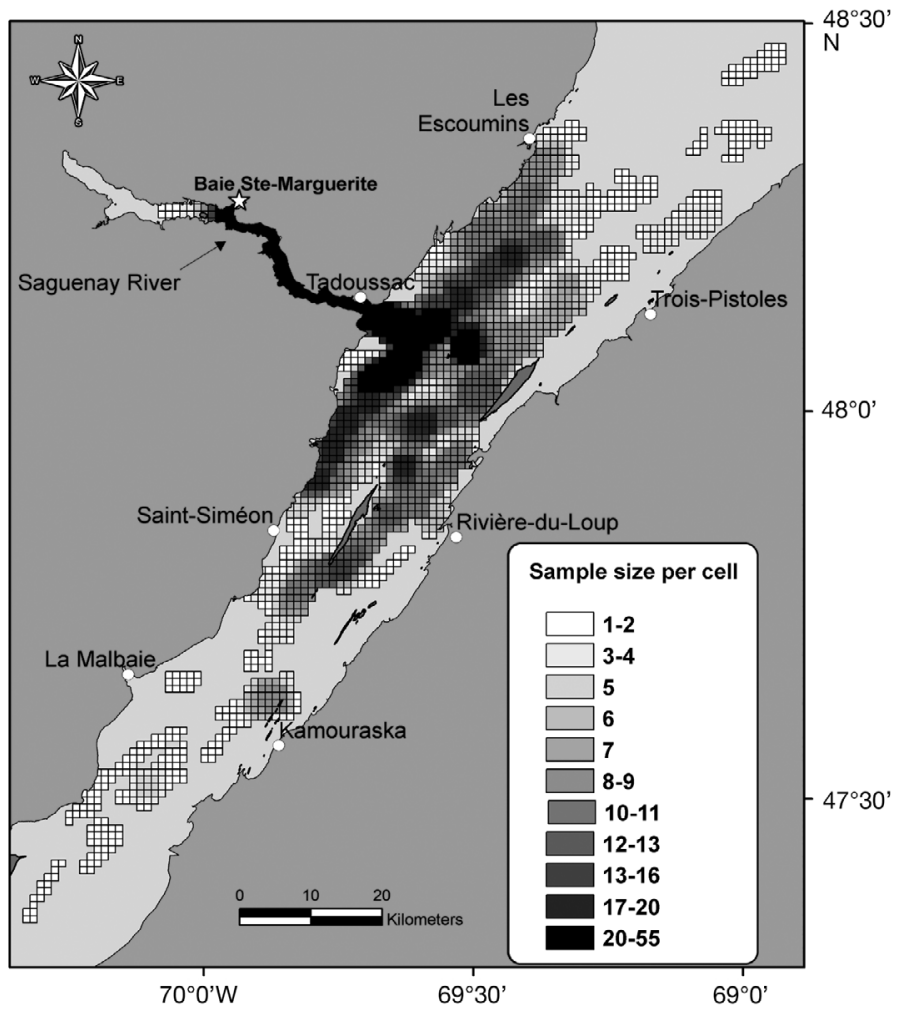

Fig. 4. Delphinapterus leucas. Number of beluga whale herd visually followed during summers 1993 to 2008, per cell of $1000 \times 1000 \mathrm{~m}$, corresponding to twice the area-restricted Search (ARS) radius of $500 \mathrm{~m}$. White cells $=1$ to 2 herd follows, and grey to black cells $=3$ to 55 herd follows

Such peaks occurred in 15 of the 38 segments (see example in Fig. 5). Var-max values were not continuously distributed and formed 2 groups, corresponding to the 2 scales where ARS arose: a 'small scale' of 300-700 $\mathrm{m}(\mathrm{n}=8$, mean $=512 \mathrm{~m})$ and a 'larger scale' of $1100-1700 \mathrm{~m}(\mathrm{n}=9$, mean $=1467 \mathrm{~m})($ Table 1$)$. The piecewise regression revealed significant differences in slopes for FPT value series (at Var-max) with recognized breakpoint(s) in 14 of the 17 series analysed (see Appendix 1). Screening the points above the $95 \%$ confidence limit of the first breakpoint for each FPT value series resulted in the identification of 33 ARS zones: 18 at the small scale and 15 at the larger scale. In 2 individuals, we identified peaks in FPT values at both scales, where small scale ARS zones were embedded within larger scale ARS zones (Fig. 5). We identified a maximum of 4 ARS zones for a single segment at a given scale.

The re-sampling of individual tracks within ARS (used to calculate the criterion for high residency in herds) resulted in an average net displacement speed threshold of $3.53 \mathrm{~km} \mathrm{~h}^{-1}$, ranging between 3.42 and $3.78 \mathrm{~km} \mathrm{~h}^{-1}$. 
Table 1. Delphinapterus leucas. Summary of the 38 segments retained for the first-passage time analysis. Area-restricted search (ARS) was identified at 2 different scales for segments 12 and 25

\begin{tabular}{|c|c|c|c|c|c|c|}
\hline $\begin{array}{l}\text { VHF } \\
\text { Track ID }\end{array}$ & Date & $\begin{array}{l}\text { Segment } \\
\text { ID }\end{array}$ & $\begin{array}{l}\text { Deployment } \\
\text { time (hh:mm) }\end{array}$ & $\begin{array}{l}\text { Displacement } \\
(\mathrm{km})\end{array}$ & $\begin{array}{c}\text { Number } \\
\text { of ARS }\end{array}$ & $\begin{array}{c}\text { ARS scale } \\
\text { (m) }\end{array}$ \\
\hline DLT0103 & 15 Aug 2001 & 1 & $6: 12$ & 30.23 & - & - \\
\hline DLT0104 & 17 Aug 2001 & 2 & $2: 34$ & 22.55 & 1 & 1600 \\
\hline DLT0205 & 6 Sep 2002 & 3 & $1: 19$ & 11.23 & - & - \\
\hline DLT0302 & 1 Jul 2003 & 4 & $4: 47$ & 18.78 & 1 & 1200 \\
\hline DLT0302 & $1 \mathrm{Jul} 2003$ & 5 & $2: 59$ & 6.31 & - & - \\
\hline DLT0303 & 30 Jul 2003 & 6 & $7: 49$ & 60.69 & - & - \\
\hline DLT0305 & 29 Aug 2003 & 7 & $2: 01$ & 12.66 & - & - \\
\hline DLT0307 & 5 Sep 2003 & 8 & $4: 40$ & 35.43 & - & - \\
\hline DLT0308 & 9 Sep 2003 & 9 & $8: 14$ & 48.42 & 4 & 1100 \\
\hline DLT0309 & 22 Sep 2003 & 10 & $5: 39$ & 41.89 & 1 & 1700 \\
\hline DLT0309 & 22 Sep 2003 & 11 & $0: 57$ & 6.91 & - & - \\
\hline DLT0401 & 16 Jun 2004 & 12 & $8: 07$ & 32.68 & 4,2 & 500,1700 \\
\hline DLT0402 & 17 Jun 2004 & 13 & $7: 54$ & 35.21 & 1 & 1400 \\
\hline DLT0403 & 22 Jun 2004 & 14 & $1: 05$ & 8.94 & - & - \\
\hline DLT0403 & 22 Jun 2004 & 15 & $2: 08$ & 11.71 & - & - \\
\hline DLT0404 & 30 Jun 2004 & 16 & $0: 41$ & 5.32 & - & - \\
\hline DLT0405 & 22 Jul 2004 & 17 & $3: 12$ & 25.84 & - & \\
\hline DLT0405 & 22 Jul 2004 & 18 & $4: 07$ & 9.53 & 1 & 300 \\
\hline DLT0406 & 28 Jul 2004 & 19 & $2: 55$ & 14.75 & 2 & 400 \\
\hline DLT0407 & 4 Aug 2004 & 20 & $8: 25$ & 49.89 & - & - \\
\hline DLT0410 & 16 Aug 2004 & 21 & $3: 37$ & 10.44 & - & - \\
\hline DLT0411 & 17 Aug 2004 & 22 & $3: 06$ & 7.01 & - & - \\
\hline DLT0411 & 17 Aug 2004 & 23 & $1: 55$ & 13.46 & - & - \\
\hline DLT0412 & 24 Aug 2004 & 24 & $3: 59$ & 12.63 & - & - \\
\hline DLT0412 & 24 Aug 2004 & 25 & $3: 46$ & 13.79 & 1,1 & 600,1600 \\
\hline DLT0413 & 20 Sep 2004 & 26 & $2: 54$ & 13.69 & - & - \\
\hline DLT0415 & 27 Sep 2004 & 27 & $2: 25$ & 11.98 & - & - \\
\hline DLT0501 & 8 Jun 2005 & 28 & $3: 22$ & 18.96 & 3 & 300 \\
\hline DLT0502 & 9 Jun 2005 & 29 & $7: 05$ & 44.05 & - & - \\
\hline DLT0502 & 9 Jun 2005 & 30 & $4: 12$ & 11.15 & 1 & 500 \\
\hline DLT0503 & 29 Jun 2005 & 31 & $9: 37$ & 51.03 & - & - \\
\hline DLT0504 & $11 \mathrm{Jul} 2005$ & 32 & $5: 31$ & 30.41 & - & - \\
\hline DLT0505 & 26 Jul 2005 & 33 & $3: 08$ & 8.60 & - & - \\
\hline DLT0505 & 26 Jul 2005 & 34 & $1: 32$ & 8.56 & - & - \\
\hline DLT0507 & 15 Aug 2005 & 35 & $8: 35$ & 44.14 & 2 & 1700 \\
\hline DLT0508 & 15 Aug 2005 & 36 & $2: 48$ & 12.51 & 3 & 700 \\
\hline DLT0509 & 18 Aug 2005 & 37 & $6: 43$ & 37.01 & 3 & 700 \\
\hline DLT0510 & 26 Aug 2005 & 38 & 9:08 & 51.19 & 2 & 1200 \\
\hline
\end{tabular}

\section{Herd visual tracking}

We retained for the analysis, a total of 772 of the 1950 herd follows that had at least 3 consecutive summary surveys separated by a constant $30 \mathrm{~min}$ interval. These were selected from years 1993 to 2008 (given small differences in sampling protocols prior to 1993) and covered the entire summer period, from June to mid-October. Selected herd follows were composed on average of 4.3 positions and were characterized by net displacement speeds varying from 0.04 to $17.84 \mathrm{~km} \mathrm{~h}^{-1}$, with an average speed of $3.49 \pm$ $2.5 \mathrm{~km} \mathrm{~h}^{-1}$. We retained the smallest scale of ARS, i.e. $500 \mathrm{~m}$, detected in the FPT analysis to grid the study area. This resulted in a fine scale grid with a cell size of $1000 \mathrm{~m}$ by $1000 \mathrm{~m}$, corresponding to twice the ARS radius of $500 \mathrm{~m}$. The herd follows retained for the analysis covered $63.2 \%\left(\mathrm{~N}=1854\right.$ cells or $\left.1765 \mathrm{~km}^{2}\right)$ of the approximated summer distribution area of the population (i.e. $2790 \mathrm{~km}^{2}$ ). This coverage was reduced to $38 \%\left(\mathrm{~N}=1108\right.$ cells or $\left.1059 \mathrm{~km}^{2}\right)$ when considering only cells visited by at least 3 herds. Using the criterion value of $3.53 \mathrm{~km} \mathrm{~h}^{-1}$ as a speed threshold, high residency occurred in $33.4 \%$ of the cells visited by at least 3 herds. Joining adjacent cells resulted in the identification of 28 areas of high residency (Fig. 6). These AHR were widely distributed across the St. Lawrence Estuary and Saguenay River (Fig. 6). 

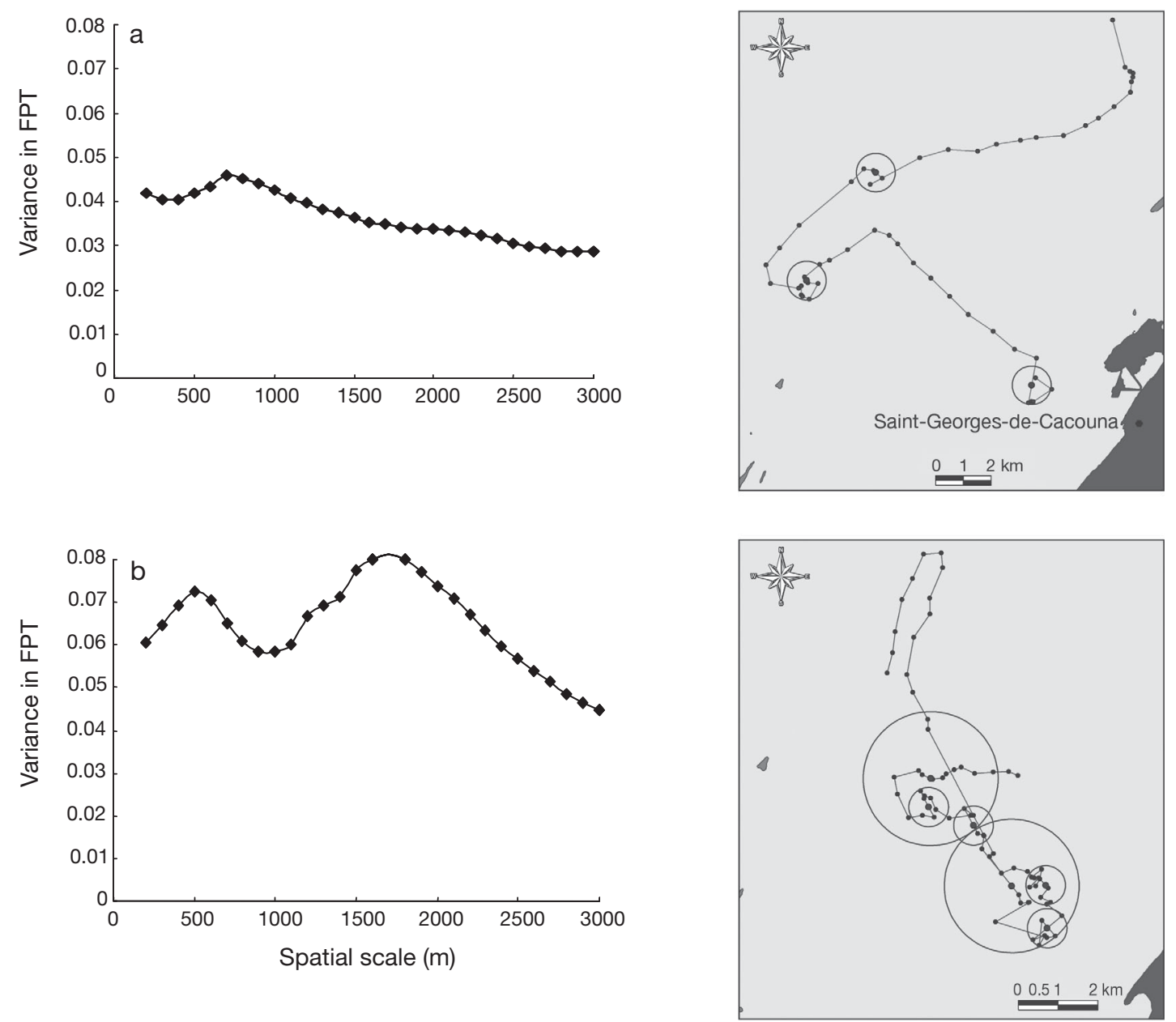

Fig. 5. Delphinapterus leucas. Example of variance in first-passage time (FPT) as a function of radius $r$ (left) with the associated segment and resulting area-restricted search zones (right). (a) Example of FPT curve with one peak at $700 \mathrm{~m}$. (b) Example of FPT curve with 2 peaks, one at $500 \mathrm{~m}$ and one at $1700 \mathrm{~m}$

The sensitivity analysis using the lower and upper extremes of the mean net displacement speeds, 3.42 and $3.78 \mathrm{~km} \mathrm{~h}^{-1}$ as criteria for high residency (i.e. $-3 \%$ and $+7 \%$ of the $3.53 \mathrm{~km} \mathrm{~h}^{-1}$ threshold covering $354 \mathrm{~km}^{2}$ ), resulted in areas of 314 and $391 \mathrm{~km}^{2}$ identified as AHR, respectively. These values respectively reduced by $3.5 \%$ and increased by $21.4 \%$ the total extent of AHR obtained when using the average threshold value $\left(3.53 \mathrm{~km} \mathrm{~h}^{-1}\right)$. One small AHR was lost when using the more severe criterion (i.e. $3.42 \mathrm{~km} \mathrm{~h}^{-1}$ ) while 2 AHR were subdivided into smaller areas. No new AHR zones appeared when using the more permissive criterion, though 2 zones fused into a larger one. The sensitivity analysis using values of $55 \%$ and $45 \%$ as triggers for defining AHR based on proportions of herds travelling below the speed threshold resulted in variations of $-7.4 \%$ and $+23.9 \%$ in the extent of AHR (i.e. 293 and $399 \mathrm{~km}^{2}$ ).
The use of the most severe criterion (55\%) resulted in the subdivision of 2 AHR into 5 smaller areas and the disappearance of 2 AHR. The use of the less restrictive criterion $(45 \%)$ resulted in the appearance of 4 AHR.

The analysis of the temporal variation in AHR led to the identification of 19 AHR for the 1993-1997 period, 22 for 1998-2003 and 25 for 2003-2008. Comparing the distribution of these AHR with that obtained using the full dataset showed that 10 AHR were not embedded or connected to a previously identified AHR. These were small AHR covering an average of $2.6 \mathrm{~km}^{2}$ (range: 2.0 to $5.0 \mathrm{~km}^{2}$ ) and were located on average $2.75 \mathrm{~km}$ (range: 1.0 to $4.5 \mathrm{~km}$ ) from a previously identified AHR. However, as the number and distribution of cells characterised by at least 3 herds varied among periods, the comparison was then repeated on 165 cells commonly retained in 
all the 3 periods. This analysis resulted in 8 AHR identified for 1993-1997 and 1998-2003, and 7 AHR for 2003-2008, 6 of which (per period) overlapped or were connected to AHR identified using the full dataset. Of the 23 AHR identified, $26 \%$ (6/23) were common to all 3 periods (i.e. either shared common or adjacent cells), and $44 \%(10 / 23)$ were common among any 2 periods, summing to $70 \%(16 / 23)$ of the AHR sharing common or adjacent cells for 2 periods or 3 periods. The remaining 30\% AHR (7/23) were located, on average, $2.1 \mathrm{~km}$ (range: 1.0 to 4.0 ) from any other common AHR.

\section{DISCUSSION}

Identifying when, where, and why animals change from one movement pattern to another constitutes an important step towards a thorough understanding of habitat use (Johnson et al. 2002, Frair et al. 2005, Nams 2005). This study, through its use of fine-scale movement data from radio-tracked individuals, presents an innovative means of analysing herd movement data acquired through visual tracking. We successfully applied a FPT approach to radiotracking data to identify ARS and scales (i.e. $500 \mathrm{~m}$ and $1500 \mathrm{~m}$ ) over which beluga likely perceived and reacted to environmental heterogeneity in the St. Lawrence Estuary. We used information on scales of occurrence of these episodes and associated net displacement speeds to develop an objective criterion to detect high residency movement patterns in visually-tracked beluga herds. Using this approach, we identified a total of 28 AHR within the St. Lawrence beluga summer distribution area.

The number of belugas that were successfully tagged $(\mathrm{N}=44)$ in this study is high compared to existing studies of cetaceans (Hooker \& Baird 1999, Laidre et al. 2002, Johnson \& Tyack 2003, Baird et al. 2005, Baird et al. 2006). Analytical requirements of the FPT analysis, however, reduced the number of usable records; some records were dropped due to short instrument retention times, while other records were truncated or also dropped due to short but significant contact losses with the tracked individual. These considerations and the geographicallyrestricted tagging effort limited the usefulness of individual tracking data to infer locations of high residency of the population as a whole over its summer range. However, sample size for tagged individuals was adequate to identify the spatio-temporal parameters of individual movement patterns leading to high residency at the herd and population levels.

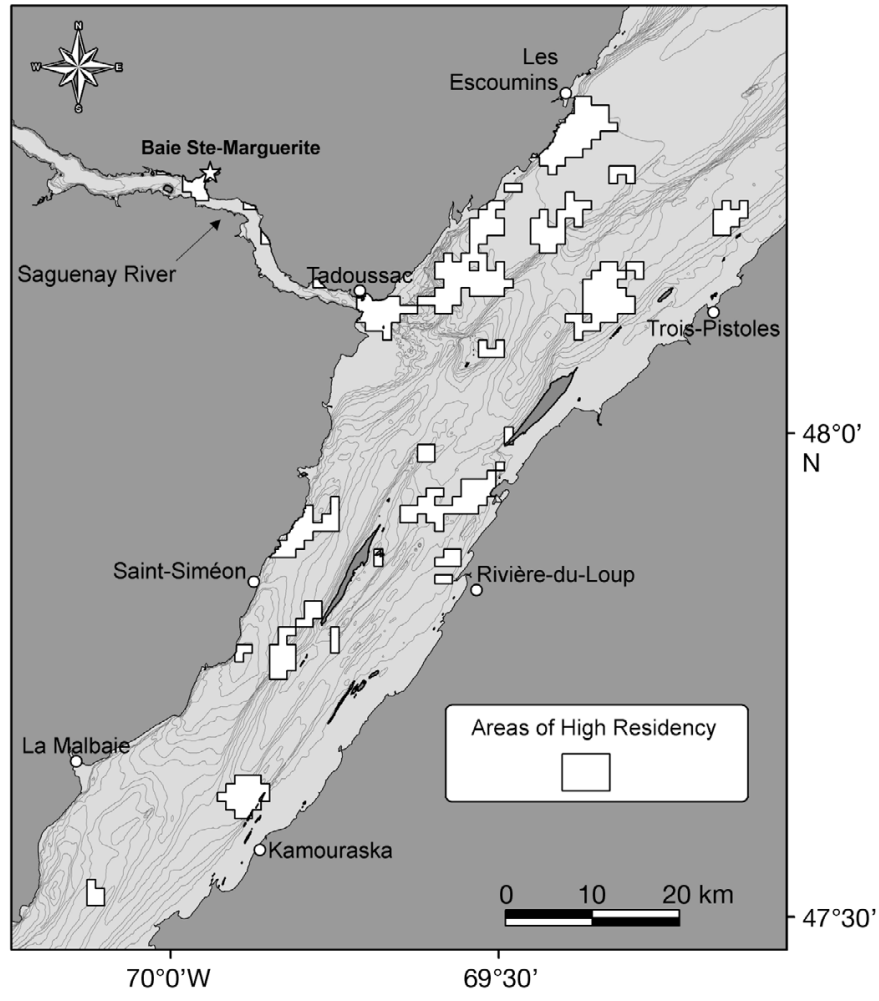

Fig. 6. Delphinapterus leucas. Areas of high residency (AHR) within the summer distribution of the St. Lawrence beluga whale population

The FPT analysis of radio-tracking records indicated that belugas, like many other marine predators, exhibited scale-specific adjustments of their movement patterns resulting in slow net displacement speeds (or ARS). Area-restricted search was performed by $38.5 \%$ of the radio-tracked individuals, a low occurrence compared to other studies having used this approach (Pinaud \& Weimerskirch 2005, Fauchald \& Tveraa 2006, Pinaud \& Weimerskirch 2007). Although species-specific functions associated with ARS may have affected their occurrence, the short duration of beluga radio-tracking records compared to other studies may have reduced the probability of capturing these events. However, as belugas have a small home range that they can cover entirely within a day, multiple 4 to $6 \mathrm{~h}$ tracks allowed sampling a significant part of their daily cycle, including activities related to ARS, although not necessarily for all the individuals sampled. The only study reporting higher occurrences of ARS for tracking periods comparable to those of our study was for bottlenose dolphins tracked in a foraging area and thus, when ARS is expected to occur regularly (Bailey \& Thompson 2006). Tagging in this study was attempted regard- 
less to where encounters took place within the study area. Therefore, no spatial bias in tagging attempts occurred that might have reduced the likelihood of capturing some ARS events.

Area-restricted search has been correlated with foraging in many species, including albatrosses and petrels (Pinaud \& Weimerskirch 2005, 2007), bottlenose dolphins (Bailey \& Thompson 2006), and ringed seals (Freitas et al. 2008). An ARS can be triggered by various environmental cues, including prey encounter rates, aggregation densities, and oceanographic features (Frair et al. 2005, Pinaud \& Weimerskirch 2005). In particular, meso-scale oceanic features, such as fronts and eddies, have often been correlated with the distribution of foraging whales profiting from their herding effects on pelagic prey (Ream et al. 2005, Campagna et al. 2006, DoniolValcroze et al. 2007, Skov et al. 2008). Once prey are located, predators might increase the tortuosity of their movements or reduce their net displacement speed further to remain within more profitable areas. These behaviours could lead to multiple-scale ARS (Fauchald \& Tveraa 2006, Pinaud \& Weimerskirch 2007) and to nested patterns of ARS (Fauchald 1999, Fauchald \& Tveraa 2006).

We documented ARS at $500 \mathrm{~m}$ and $1500 \mathrm{~m}$ scales, suggesting that factors affecting movement decisions of St. Lawrence belugas occurred at 2 scales. Many meso-scale oceanic processes occur in the Estuary, and some of these features (e.g. eddies) operate at scales comparable to those of the ARS observed in St. Lawrence beluga (Ingram \& El-Sabh 1990). These meso-scale features can act as environmental cues to which beluga respond, and may serve to aggregate prey (Marchand et al. 1999). Belugas feed on a wide variety of prey, ranging from small polychaete worms to large fish such as salmon (Vladykov 1946, Sergeant 1973), many of which show patchy distributions. Behaviours suggestive of ARS were described for belugas in the High Arctic moving 'very little distance horizontally' when suspected to be foraging on patchily distributed Greenland halibut (Martin \& Smith 1992, 1999). Pippard \& Malcolm (1978) also described foraging in belugas as being characterized by individuals going back and forth within limited areas where they executed tight circles, half circles and reversals of direction. Similar movement patterns were described by Watts \& Draper (1986) when observing Hudson Bay beluga foraging on capelin aggregations. These descriptions of movement patterns of foraging belugas present a good correspondence with the definition of ARS and behaviours documented in this study.
The assumption that ARS represents foraging activities is probably adequate when behaviours other than foraging are not likely to occur, as may be the case in studies of central-place foragers involved in foraging trips (Fauchald \& Tveraa 2003). Although stomach contents indicate that beluga feed during summer in the Estuary (Vladykov 1946; V. Lesage, DFO, unpubl. data), the overall occurrence of ARS behaviours related to foraging may be less frequent in beluga during summer than in other species or at other times of the year, given that other behaviours such as calving are expected to also take place during summer. However, given that FPT analyses aim at quantifying variation in search effort along an animal's path, any behaviour that results in an animal investing more time within a particular area could lead to the detection of peaks in variance of FPT, from which ARS is deduced. In other words, episodes of ARS may well represent behaviours other than foraging. In this study, various activities, including foraging, were expected to be sampled, and any behaviour leading to larger time investments within particular zones were of interest. However, their specific identification was beyond the scope of this study.

Similarly, the specific biological functions associated with the AHRs identified in this study could not be established with the present analysis. In the Arctic, belugas congregate in river mouths during summer where they spend extensive periods of time as a result of various possible activities including calving, feeding, breeding, moulting, and social interactions (reviewed in Lesage \& Kingsley 1998). Historically, beluga also formed large concentrations in river mouths in the St. Lawrence Estuary during summer (e.g. near Manicouagan and Rivière-Ouelle) (Vladykov 1944). They still congregate in areas of shallow water today (e.g. Baie Ste-Marguerite in the Saguenay River), possibly for the same reasons as in the Arctic or for a combination of activities (Pippard 1985b, Chadenet 1997). Various studies have also proposed possible functions, such as feeding and calving (Pippard \& Malcolm 1978, Michaud et al. 1990, Lesage \& Kingsley 1998), for some areas which are overlapping with the AHR that were identified in the present study. However, these past studies were based largely on circumstantial evidences or anecdotal observations.

Eighteen summer areas of 'intensive use' for St. Lawrence beluga have been previously defined based on systematic vessel and aerial transects conducted between 1986 and 1992 (Fig. 7). Intensity of use was based on the number of belugas and frequency of occurrence in a given area during re- 
peated surveys. Conclusions were drawn from repeated snapshots of distribution patterns (Eulerian approach), where repeated sightings of large numbers of beluga were interpreted as an index of high usage. This approach is, however, inadequate for non-systematic data (such as those often collected during opportunistic encounters with marine mammals) as unequal search effort may introduce biases in observed patterns. In the current study, conclusions were based on repeated longitudinal tracking of herd movements (Lagrangian approach), where a slow net displacement speed of a majority of herds was used to define high residency, which was believed to occur in the most profitable habitats. While this approach provided direct information on the time spent in each sector when used, it could not address the frequency of use of these sectors due to the non-uniform distribution of herd follows. Despite differences in methodology and study period, many areas of 'intensive use' identified by Michaud (1993) overlapped with the AHR identified in the present study (Figs. 6 \& 7), underscoring their significance for St. Lawrence belugas, although life processes associated with each area remain uncertain.

The sensitivity analyses indicated a certain robustness of the AHR areas to changes in the definition of criteria, although they suggested caution concerning the exact locations of their boundaries. The few cells with marginal values (i.e. appearing or disappearing depending on criterion) are not necessarily indicative of lower habitat quality. The function of a given sector may simply vary over time and be used as an AHR during relatively short periods over various temporal scales. This restricted use of a sector might then translate into a lower probability of detecting herds involved in behaviours leading to AHR, and consequently, in a lower percentage of herds with travelling speeds below the threshold. Marine environments are influenced by physical processes acting over multiple temporal scales (such as tidal and lunar cycles, seasons and years) and high quality habitats can be highly ephemeral in such dynamic systems but may also be predictably recurrent.

Longer-term changes in ecosystem structures might also affect predator habitat use. Although no detailed information on ecosystem changes of the Estuary is available at present, major changes in ecosystem structure were documented over the last few decades in the nearby ecosystem of the Gulf of St. Lawrence following the collapse of the groundfish stocks (Savenkoff et al. 2007a,b) that warranted an investigation of long-term stability in beluga habitat

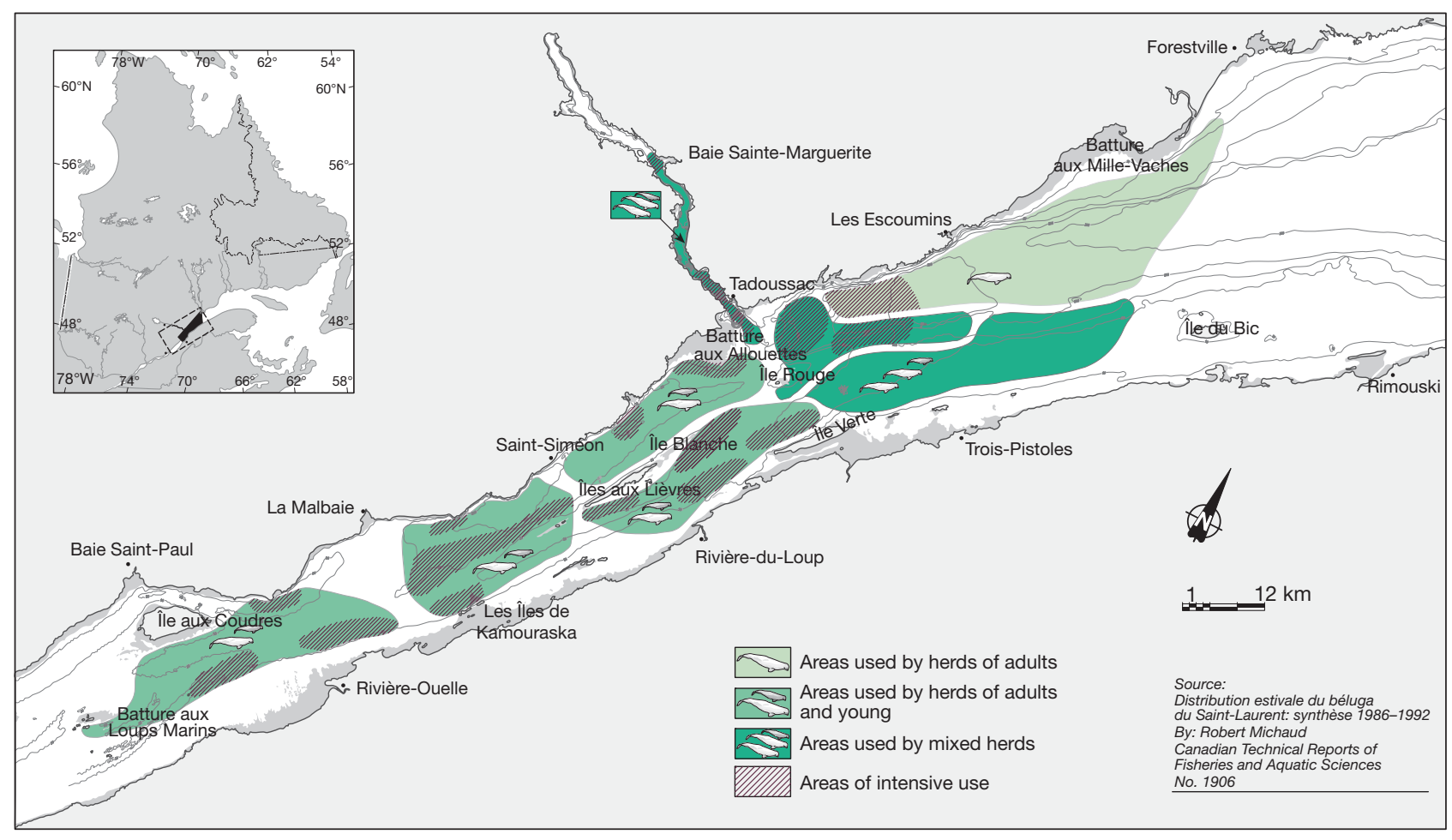

Fig. 7. Delphinapterus leucas. Summer range of the St. Lawrence beluga whale population with the areas used by the different type of herds (green shapes) and the areas of intensive use (hatched areas). Modified from Michaud (1993) 
use in the Estuary. Repeating the analysis for 3 time periods revealed small variations in the number and distribution of AHR among periods. These variations could be related to ecosystem changes but were more likely related to a reduction in total sample size, because, for cells with adequate sample sizes in all 3 periods, the observed variations resulted in only small displacement ( 1 to $4 \mathrm{~km}$ ) in AHR across years. These results indicate that the AHR identified using the full dataset provides a reliable representation of habitat use by the St. Lawrence beluga population over the span of the study period.

The database of herd follows used in this study to assess patterns of residency of St. Lawrence beluga was of a high standard, considering the consistency of visual survey methods over the years, as well as their total span (16 yr) and spatial distribution, which covered, in some years, the population's entire summer distribution. The selection and nonuniform distribution of herd follows may have resulted in some AHR having gone undetected in sectors with lower sampling effort such as those located outside of the central portion of the summer distribution (Fig. 4). However, in the central sectors, an increase in sample size would most likely not have substantially influenced the distribution of the AHR given that cells characterized by a smaller sample size and identified as part of AHR were regularly found adjacent to cells characterized by larger sample size that were either part or not of AHR (Figs. 4 \& 6). Moreover, many cells adjacent to those with large sample sizes were characterized by a total absence of herd follows, indicating that, over the years, the research vessel spent considerable time in visual range of or in these areas, but that no beluga herds were detected there. This may indicate a systematic avoidance of these areas by belugas. Conversely, many cells with large sample sizes were not identified as being part of an AHR as a majority of herds had net displacement speeds above the selected threshold. These results suggest that belugas consistently moved more quickly in those cells. Pippard (1985a) identified travelling corridors for belugas, particularly within the Saguenay River, and our observations support the existence of travelling corridors in this population. Although it was not the intent here, our method could be used to identify travelling routes provided that a speed threshold associated with these movement patterns could be identified.

The coarse temporal (sampling interval of several min) and spatial (large herd radius) resolution and short duration (few positions) typical of marine mam- mal herd follows makes this type of data less suitable for analysis using common techniques (e.g. correlated random walk, state space models, fractal, FPT, etc.). The method we present here overcame this challenge by using herd follows to extend individual movement analysis to the scale of a population and identify areas of high residency. Currently in the literature, the limited accounts of residency patterns usually refer to the amount of time an individual, a group or a species were continuously observed within a specific area (Jaquet et al. 2003, Martin \& da Silva 2004, Lusseau 2005, Parra et al. 2006, Bearzi et al. 2008). This study examines an approach based on herd tracking rather than site tracking, which constitutes a more powerful means of studying habitat preferences. Data of this nature (i.e. opportunistic herd tracking data) exist for several marine mammal species and could be explored using methods similar to those presented here.

The identification of AHR could also be important for the conservation of the St. Lawrence beluga whale as it provides the first quantitative account of areas of importance for this population. Moreover, the strong overlap between the AHR and areas already recognised as potentially important (Pippard \& Malcolm 1978, Michaud 1993) underlines that these areas likely serve special purposes for this population. The approach developed here also defined AHR according to scales and cell sizes that are meaningful in the context of conservation or definition of management units (Nams et al. 2006). Identifying areas where individuals spent time, such as the AHR, could further be important in understanding and measuring the effects of factors limiting population growth. In the St. Lawrence estuary, such limiting factors could include exposure to noise, which may have negative effects on belugas through temporary or permanent hearing loss, masking of natural sounds, reduction of communication efficiency, and increase in stress level (Lesage et al. 1999).

However, understanding how AHR support critical aspects of the life cycle of this population will necessitate a thorough understanding of their functions and characteristics. This could be carried out by further studying St. Lawrence beluga whales' diving and surface behaviours and how they are related to different habitat physical and biological characteristics, such as current patterns, water temperature and salinity, sediment types, and prey abundance and distribution. Such analyses were far beyond the scope of the present study but represent the next steps toward the identification and conservation of critical habitats for this endangered population. 
Acknowledgements. We are grateful to our colleagues who helped collect the data, especially M. Moisan, M.-H. D'Arcy, P. Moisan and R. Pintiaux from the GREMM, and Y. Morin and C. Guimont from DFO. We also thank R.W. Baird for his inputs in designing the VHF/TDR package, A. Mosnier and P. Fauchald for access to their scripts for the FPT analysis, and to M. Humphries for comments on an earlier version of the manuscript. This research was funded by the Species At Risk Program of Fisheries and Oceans Canada, the Group of Research and Education on Marine Mammals, the St. Lawrence National Institute of Ecotoxicology, the Interdepartmental Research Fund of Environment Canada, the Saguenay-St. Lawrence Marine Park, the Fondation de la Faune du Québec, Parks Foundation and the National Oceanic and Atmospheric Administration.

\section{LITERATURE CITED}

Austin D, Bowen WD, McMillan JI (2004) Intraspecific variation in movement patterns: modeling individual behaviour in a large marine predator. Oikos 105:15-30

Bailey H, Thompson P (2006) Quantitative analysis of bottlenose dolphin movement patterns and their relationship with foraging. J Anim Ecol 75:456-465

Baird RW, Hanson MB, Dill LM (2005) Factors influencing the diving behaviour of fish-eating killer whales: sex differences and diel and interannual variation in diving rates. Can J Zool 83:257-267

Baird RW, Webster DL, McSweeney DJ, Ligon AD, Schorr GS, Barlow J (2006) Diving behaviour of Cuvier's (Ziphius cavirostris) and Blainville's (Mesoplodon densirostris) beaked whales in Hawai'i. Can J Zool 84: 1120-1128

Barraquand F, Benhamou S (2008) Animal movements in heterogeneous landscapes: identifying profitable places and homogeneous movement bouts. Ecology 89: 3336-3348

Bearzi G, Agazzi S, Bonizzoni S, Costa M, Azzellino A (2008) Dolphins in a bottle: abundance, residency patterns and conservation of bottlenose dolphins Tursiops truncatus in the semi-closed eutrophic Amvrakikos Gulf, Greece. Aquat Conserv 18:130-146

Campagna C, Piola AR, Marin MR, Lewis M, Fernández T (2006) Southern elephant seal trajectories, fronts and eddies in the Brazil/Malvinas Confluence. Deep-Sea Res Part I Oceanogr Res Pap 53:1907-1924

Cañadas A, Hammond PS (2008) Abundance and habitat preferences of the short-beaked common dolphin Delphinus delphis in the southwestern Mediterranean: implications for conservation. Endang Species Res 4: 309-331

Chadenet V (1997) Fréquentation et bilan d'activité du béluga (Delphinapterus leucas) du Saint-Laurent dans la Baie Sainte-Marguerite. MS thesis, Université Laval, Quebec

COSEWIC (2004) Assessment and update status report on the beluga whales Delphinapterus leucas in Canada. Committee on the Status of Endangered Wildlife in Canada, Ottawa

> Doniol-Valcroze T, Berteaux D, Larouche P, Sears R (2007) Influence of thermal fronts on habitat selection by four rorqual whale species in the Gulf of St. Lawrence. Mar Ecol Prog Ser 335:207-216

Fauchald P (1999) Foraging in a hierarchical patch system. Am Nat 153:603-613
Fauchald P, Tveraa T (2003) Using first-passage time in the analysis of area-restricted search and habitat selection. Ecology 84:282-288

Fauchald P, Tveraa T (2006) Hierarchical patch dynamics and animal movement pattern. Oecologia 149:383-395

Frair JL, Merrill EH, Visscher DR, Fortin D, Beyer HL, Morales JM (2005) Scales of movement by elk (Cervus elaphus) in response to heterogeneity in forage resources and predation risk. Landsc Ecol 20:273-287

Freitas C, Kovacs KM, Ims RA, Fedak MA, Lydersen C (2008) Ringed seal post-moulting movement tactics and habitat selection. Oecologia 155:193-204

> Hooker SK, Baird RW (1999) Deep-diving behaviour of the northern bottlenose whale, Hyperoodon ampullatus (Cetacea: Ziphiidae). Proc R Soc Lond B Biol Sci 266: $671-676$

Ingram RG, El-Sabh MI (1990) Fronts and meso-scale features in the St. Lawrence Estuary. In: El-Sabh MI, Silverberg N (eds) Oceanography of a large-scale estuarine system: the St. Lawrence. Springer-Verlag, Berlin, p 71-93

Jaquet N, Gendron D, Coakes A (2003) Sperm whales in the Gulf of California: residency, movements, behavior, and the possible influence of variation in food supply. Mar Mamm Sci 19:545-562

Johnson MD (2007) Measuring habitat quality: A review. Condor 109:489-504

> Johnson AR, Wiens JA, Milne BT, Crist TO (1992) Animal movements and population-dynamics in heterogeneous Landscapes. Landsc Ecol 7:63-75

Johnson CJ, Parker KL, Heard DC, Gillingham MP (2002) Movement parameters of ungulates and scale-specific responses to the environment. J Anim Ecol 71:225-235

Johnson MP, Tyack PL (2003) A digital acoustic recording tag for measuring the response of wild marine mammals to sound. IEEE J Ocean Eng 28:3-12

> Jonsen ID, Myers RA, James MC (2006) Robust hierarchical state-space models reveal diel variation in travel rates of migrating leatherback turtles. J Anim Ecol 75: 1046-1057

Laidre KL, Heide-Jørgensen MP, Dietz R (2002) Diving behaviour of narwhals (Monodon monoceros) at two coastal localities in the Canadian High Arctic. Can J Zool 80:624-635

Laidre KL, Heide-Jørgensen MP, Logdson ML, Hobbs RC and others (2004) Seasonal narwhal habitat associations in the high Arctic. Mar Biol 145:821-831

Lesage V, Kingsley MCS (1998) Updated status of the St. Lawrence River population of the beluga Delphinapterus leucas. Can Field Nat 112:98-113

> Lesage V, Barrette C, Kingsley MCS, Sjare B (1999) The effect of vessel noise on the vocal behavior of belugas in the St. Lawrence River estuary, Canada. Mar Mamm Sci 15:65-84

- Lusseau D (2005) Residency pattern of bottlenose dolphins Tursiops spp. in Milford Sound, New Zealand, is related to boat traffic. Mar Ecol Prog Ser 295:265-272

Marchand C, Simard Y, Gratton Y (1999) Concentration of capelin (Mallotus villosus) in tidal upwelling fronts at the head of the Laurentian Channel in the St. Lawrence estuary. Can J Fish Aquat Sci 56:1832-1848

Martin AR, da Silva VMF (2004) Number, seasonal movements, and residency characteristics of river dolphins in an Amazonian floodplain lake system. Can J Zool 82: 1307-1315 
Martin AR, Smith TG (1992) Deep diving in wild, free-ranging beluga whales, Delphinapterus leucas. Can J Fish Aquat Sci 49:462-466

Martin AR, Smith TG (1999) Strategy and capability of wild belugas, Delphinapterus leucas, during deep, benthic diving. Can J Zool 77:1783-1793

Michaud R (1993) Distribution estivale du béluga du St.Laurent: synthèse 1986 à 1992. Can Tech Rep Fish Aquat Sci, no. 1906

Michaud R, Vezina A, Rondeau N, Vigneault Y (1990) Annual distribution and preliminary characterization of beluga (Delphinapterus leucas) habitats in the St. Lawrence. Can Tech Rep Fish Aquat Sci, no. 1757

Mosnier A, Lesage V, Gosselin JF, Lemieux Lefebvre S, Hammill MO, Doniol-Valcroze T (2010) Information relevant to the documentation of habitat use by St. Lawrence beluga (Delphinapterus leucas), and quantification of habitat quality. DFO Canadian Science Advisory Secretariat, Research Document. Report no. 2009/098

Nams VO (2005) Using animal movement paths to measure response to spatial scale. Oecologia 143:179-188

- Nams VO, Mowat G, Panian MA (2006) Determining the spatial scale for conservation purposes - an example with grizzly bears. Biol Conserv 128:109-119

Parra GJ, Corkeron PJ, Marsh H (2006) Population sizes, site fidelity and residence patterns of Australian snubfin and Indo-Pacific humpback dolphins: implications for conservation. Biol Conserv 129:167-180

Pinaud D (2008) Quantifying search effort of moving animals at several spatial scales using first-passage time analysis: effect of the structure of environment and tracking systems. J Appl Ecol 45:91-99

Pinaud D, Weimerskirch H (2005) Scale-dependent habitat use in a long-ranging central place predator. J Anim Ecol 74:852-863

Pinaud D, Weimerskirch H (2007) At-sea distribution and scale-dependent foraging behaviour of petrels and albatrosses: a comparative study. J Anim Ecol 76:9-19

Pippard L (1985a) Patterns of movement of the St. Lawrence White Whales (Delphinapterus leucas). Technical report, Canadian Wildlife Service and Parks Canada, Ottawa

Pippard L (1985b) Status of the St.Lawrence River population of beluga, Delphinapterus leucas. Can Field Nat 99: 438-450

Pippard L, Malcolm T (1978) White whales Delphinapterus leucas: observations on their distribution, population and critical habitats in the St Lawrence and Saguenay Rivers. Project Report C1632, Department of Indian and Northern Affairs, Park Canada, Ottawa

Pyke GH (1978) Optimal foraging: movement patterns of bumblebees between inflorescences. Theor Popul Biol 13:72-98

Ream RR, Sterling JT, Loughlin TR (2005) Oceanographic features related to northern fur seal migratory movements. Deep-Sea Res II Top Stud Oceanogr 52:823-843

Russell RE, Swihart RK, Feng ZL (2003) Population consequences of movement decisions in a patchy landscape. Oikos 103:142-152

Savenkoff C, Castonguay M, Chabot D, Hammill MO, Bourdages H, Morissette L (2007a) Changes in the northern Gulf of St. Lawrence ecosystem estimated by inverse modelling: evidence of a fishery-induced regime shift? Estuar Coast Shelf Sci 73:711-724

Savenkoff C, Swain DP, Hanson JM, Castonguay Mand others (2007b) Effects of fishing and predation in a heavily exploited ecosystem: comparing periods before and after the collapse of groundfish in the southern Gulf of St. Lawrence (Canada). Ecol Model 204:115-128

Sergeant DE (1973) Biology of white whales (Delphinapterus leucas) in Western Hudson Bay. J Fish Res Board Canada 30:1065-1090

Skov H, Gunnlaugsson T, Budgell WP, Horne J and others (2008) Small-scale spatial variability of sperm and sei whales in relation to oceanographic and topographic features along the Mid-Atlantic Ridge. Deep-Sea Res II Top Stud Oceanogr 55:254-268

> Turchin P (1991) Translating foraging movements in heterogeneous environments into the spatial-distribution of foragers. Ecology 72:1253-1266

Turchin P (1998) Quantitative analysis of movement patterns: measuring and modeling population redistribution in animals and plants. Sinauer Associates, Sunderland, MA

van Horne B (1983) Density as a misleading indicator of habitat quality. J Wildl Manag 47:893-901

Vladykov VD (1944) Étude sur les mammifères aquatiques. III. Chasse, biologie, et valeur économique du marsouin blanc ou béluga (Delphinapterus leucas) du fleuve et du golfe Saint-Laurent. Département des pêcheries, Québec

Vladykov VD (1946) Étude sur les mammifères aquatiques. IV. Nourriture du marsouin blanc (Delphinapterus leucas) du fleuve Saint-Laurent. Département des pêcheries, Québec

Watts PD, Draper BA (1986) Note on the behavior of beluga whales feeding on capelin. Arct Alp Res 18:439

Whitehead H (2004) The group strikes back: follow protocols for behavioral research on cetaceans. Mar Mamm Sci 20:664-670

Zar JH (1999) Biostatistical analysis. Prentice Hall, Upper Saddle River, NJ 
Appendix 1. A method for the identification of multiple area-restricted search (ARS) zones within a single individual track using piecewise regressions on first-passage time (FPT) values

Since it is reasonable to assume that an individual could display area-restricted search many times, we developed a method to identify multiple ARS zones within a given segment. We used piecewise regressions to detect breakpoints in FPT values at a given scale to detect transitions between ARS-related behaviours and other behaviours. To define these breakpoints, we classified FPT values (at the scale of Var-max) in ascending order for each segment (e.g. Fig. $A 1 \mathrm{a}, \mathrm{c})$. We then applied a 2- and 3-process (1 and 2 breakpoints) piecewise-regression model to the data series using the MODEL procedure in SAS (SAS Institute 2003). To fulfill model assumptions, we corrected heteroscedasticity and auto-correlation of residuals using the FIT statement of the MODEL procedure. The continuous function for the one-breakpoint model took the following form:

$$
\begin{aligned}
& y=a_{1}+b_{1} x \quad \text { for } c_{1} \geq x \\
& y=\left\{a_{1}+c_{1}\left(b_{1}-b_{2}\right)\right\}+b_{2} x \quad \text { for } c_{1}<x
\end{aligned}
$$

whereas the continuous function for the 2-breakpoints model took the following form:

$$
\begin{aligned}
& y=a_{1}+b_{1} x \\
& y=\left\{a_{1}+c_{1}\left(b_{1}-b_{2}\right)\right\}+b_{2} x \\
& \left.y=\left\{a_{1}+c_{1}\left(b_{1}-b_{2}\right)\right\}+c_{2}\left(b_{2}-b_{3}\right)\right\}+b_{3} x \text { for } x>c_{2}
\end{aligned}
$$

where $y$ represents the FPT value, $x$ the order of the FPT value, $a_{i}$ the origin of the regression line $i, b_{i}$ the slope of the regression line $i$ and $C_{i}$ the breakpoint(s) separating regression lines. The piecewise regressions thus resulted in the ordered FPT value series being described by 1, 2 or 3 regression lines (e.g. Fig. A1a,c).

For FPT series described by 2 or 3 regression lines, significant differences between regression coefficients were tested using Student's $t$-tests (Zar 1999). When regression coefficients differed significantly, the associated FPT value series were analysed further to identify potential occurrence of multiple ARS zones. In order to do this, all interpolated points used to establish the second or third regression lines (precisely, any point over the $95 \%$ confidence interval value of breakpoint (1)) were considered as potential centers for an ARS zone (e.g. Fig. A1a,c).

Interpolated points were extracted and mapped using ArcGIS with their corresponding radius (equal to Var-max). As in regular FPT analysis, we considered the point with the highest FPT value as the center of the first ARS zone. Then, starting with the second highest FPT value, we screened points one by one to identify other potential spatially distinct ARS zones. We considered a point to be the centre of a new ARS zone when the circle (of a radius equal to Var-max) associated with this point did not overlap with another ARS zone. We repeated this step until no more point above the threshold could be considered as a new ARS zone centre, based on the aforementioned criteria.
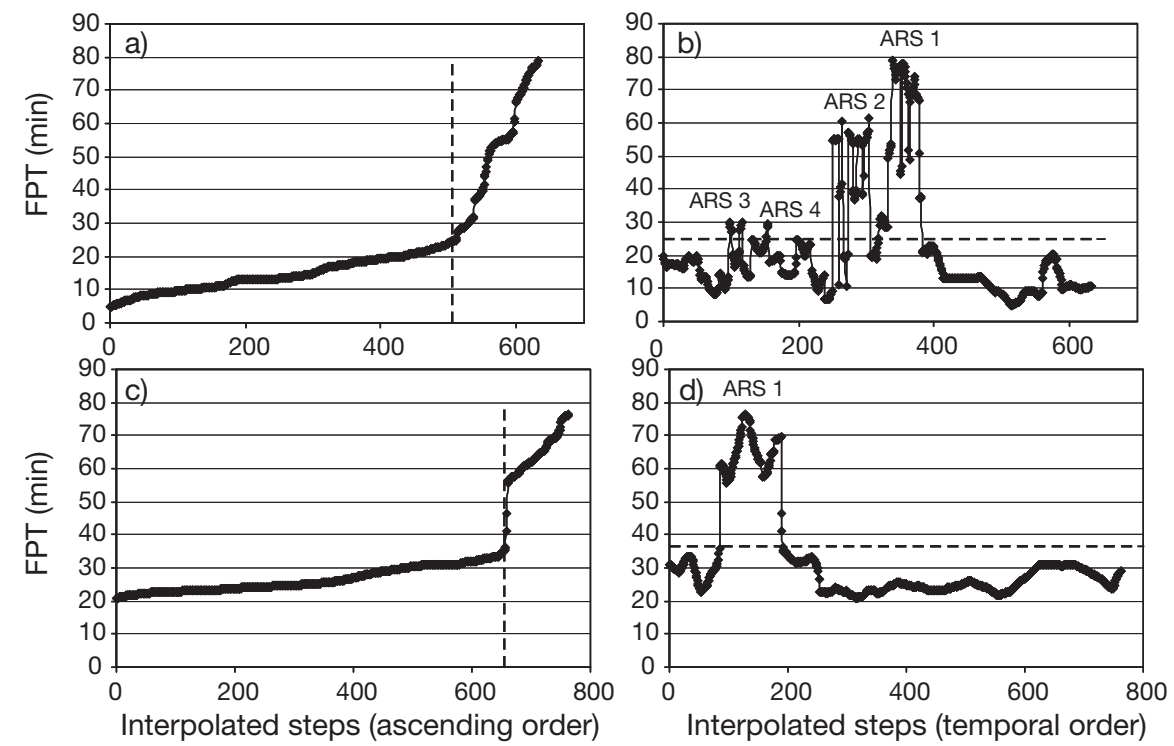

Fig. A1. Delphinapterus leucas. Examples of the piecewise regression analysis presenting a first-passage time (FPT) value series with 2 regression lines (1breakpoint model) (a and b), and 3 regression lines (2-breakpoints model) (c and d). (a) FPT values series are presented in ascending order for segment 12 at the $500 \mathrm{~m}$ scale (dashed line indicating the first break-point, $c_{1}$ ). (b) FPT values series are in temporal order with identified threshold and arearestricted search (ARS) zones for segment 11. (c) FPT values series are in ascending order for segment 18 at the $300 \mathrm{~m}$ scale. (d) FPT values series are in temporal order with identified threshold and ARS zone for segment 9
Editorial responsibility: Peter Corkeron, Woods Hole, Massachusetts, USA
Submitted: May 26, 2011; Accepted: December 20, 2011

Proofs received from author(s): March 12, 2012 